Journal of Molecular and Cellular Cardiology

Review

\title{
Novel Molecular Mechanisms and Regeneration Therapy for Heart Failure
}

Toru Oka ${ }^{1,2}$, Hiroyuki Morita ${ }^{3}$ and Issei Komuro ${ }^{2,3}$

${ }^{1}$ Onco-Cardiology Unit, Department of Cardiology, Osaka Medical Center for Cancer and Cardiovascular Diseases, 1-3-3 Nakamichi, Higashinari-ku, Osaka 537-8511, Japan

${ }^{2}$ Japan Science and Technology Agency, CREST, Tokyo, Japan

${ }^{3}$ Department of Cardiovascular Medicine, The University of Tokyo Graduate School of Medicine, 7-3-1 Hongo, Bunkyo-ku, Tokyo 113-8655, Japan

Correspondence: Toru Oka, E-mail; oka-to@mc.pref.osaka.jp or Issei Komuro, E-mail komuro-tky@umin.ac.jp 


\begin{abstract}
Heart failure (HF) is one of the leading causes of mortality in the world. Various molecular mechanisms have been proposed for $\mathrm{HF}$, but its precisemechanisms are still largely unknown. In this review, summarizing the "President's Distinguished Lecture Award” of XX World Congress of International Society for Heart Research 2010 in Kyoto, Japan, we introduce recent our studies on HF, including 1) p53-induced suppression of Hif-1-induced angiogenesis as a novel mechanism of HF, 2) angiogenesis as a potential therapeutic strategy for HF, and 3) IGFBP-4 as a novel factor for cardiomyogenesis by inhibiting canonical Wnt signaling.
\end{abstract}




\section{Contents}

1. Introduction

2. Angiogenesis in hypertrophied hearts

3. Angiogenesis in failing hearts

4. p53 inhibits Hif-1 in hypoxic myocardium

5. Angiogenesis as a potential therapeutic strategy for heart failure

6. IGFBP-4 is a novel cardiogenic factor by inhibiting Wnt/ $\beta$-catenin signaling

7. Conclusion

Disclosure statement

Acknowledgements

References 


\section{Introduction}

Heart failure (HF), one of the leading causes of mortality in the world, is a complex disorder that leads to a disturbance of the normal pumping of blood to the peripheral organs to meet the metabolic demands of the body.There are two forms of heart failure, heart failure with reduced ejection fraction (HFrEF) and heart failure with preserved ejection fraction (HFpEF). In this review, we focus on systolic heart failure (HFrEF) and discuss about its molecular mechanisms and its novel therapies based on the mechanisms.

Under the conditions of pathological stimuli due to the cardiovascular diseases such as hypertension, valvular diseases and myocardial infarction, the heart initially maintains cardiac function by adaptive mechanisms such as cardiac hypertrophy and dilatation. If the hemodynamic overload is prolonged, however, the ventricular contractility is gradually decreased. Numerous studies have proposed a variety of molecular mechanisms of the transition from cardiac hypertrophy to HF. These mechanisms include, 1) myocyte growth with reemployment of fetal gene programs and decreased adult gene expressions[1],2) alterations of proteins associated with intracellular $\mathrm{Ca}^{2+}$ handling, which play important roles in excitation-contraction coupling [2], 3) myocyte death[3], 4) changes in the extracellular matrix[4, 5], 5) oxidative stress[6], 6)changes ofmetabolism and energetics[7], 7) over-activation of neurohormones (e.g., norepinephrine and angiotensin II) and their receptors [8], inflammatory cytokines (e.g., tumor necrosis factor-alpha [TNF- $\alpha$ ])[9], other peptides and growth factors (e.g., transforming growth factor-beta [TGF- $\beta$ ],endothelin)[10, 11], and8) gene mutations and epigenetic changes[12]. All of these alterations may cause HF, 
however, the precise mechanisms of HF are still largely unknown.

\section{Angiogenesis in hypertrophied hearts}

In HF patients due to valvular diseases, ${ }^{201} \mathrm{Tl}$ myocardial SPECT studyhas demonstrated that left ventricular systolic function is negatively associated with myocardial perfusion abnormality[13], suggesting that myocardial blood flowis an important regulatorof cardiac function. In growing organs or tissues such as hypertrophied heart and cancer, angiogenesisis necessary to maintain their functions. Physiological cardiac hypertrophy induced during development and by exercise is accompanied with angiogenesis[14], while pathological cardiac hypertrophy induced by hemodynamic overload is not accompanied with angiogenesis, leading to myocardial ischemia andcardiac dysfunction known as "hibernation"[14]. In murine model of Akt-induced cardiac hypertrophy, hypertrophic stimuli induced expressions of vascular endothelial growth factor (VEGF) and angiopoietin 2 genes in the adaptive phase of hypertrophy, and inhibition of VEGF signaling with neutralizing antibody reduced capillary density of the myocardium, resulting in an early transition to $\mathrm{HF}[15]$.Furthermore, the transition from adaptive hypertrophy to HF induced by pressure overload was accelerated due to insufficiency of myocardial capillary induction in VEGF deficient mice [16].

A zinc-finger transcription factor GATA4 is reported to be one of the regulators of VEGF[17]. GATA4 binds to transactivation domain of the Vegf-A gene and regulates Vegf-A expression [17]. GATA4 is expressed in cardiomyocytes from early embryo to 
adult[18]. Cardiac-specific deletion of GATA4 revealed its pivotal roles incardiac hypertrophy, stress-responses of the heart, myocyte viability as well as regulation of cardiac genes [19]. Endogenous GATA4 protein is kept at low levels in the steady state of the adult heart, but is upregulated in hypertrophied heart in response to pressure overload associating with increased capillary density. In decompensated failing heart, however, GATA4 protein is decreased parallel with capillary density. Taken together, GATA4 directly modifies the angiogenic program regulating Vegf-A gene expression in the adult heart [20] (Figure 1).To explore the regulation of myocardial angiogenesisduring the transition from compensated cardiac hypertrophy to decompensated HF, we examined murine pressure overload model.

\section{Angiogenesis in failing hearts}

Transverse aortic constriction (TAC) acutely induces pressure overloadon the left ventricle.Initially,TAC induces compensated cardiac hypertrophy (adaptive phase),however, prolonged pressure overloaddepresses myocardial contractility resulted in decompensateHF (maladaptive phase)[21]. It has been thought that not only insufficient hypertrophy but also a depression of the myocardium's intrinsic contractility cause afterload mismatch and HF[22], however, the precise molecular mechanism by which pressure overload induces cardiac dysfunction remains unclear. After TAC, cardiac hypertrophy indicated by the increases in heart weight-body weight ratio and ventricular wall thicknesswere gradually enhanced, peaked on day 14 after TAC and not 
changed afterward[21]. Noteworthy, cardiac function was preserved until day 14, but significantly reduced at day 28 after TAC.Histological analysis revealed that capillary density was increased during adaptive phase but decreased thereafter[21], resulting in hypoxia in the failing heart, suggesting the important role of angiogenesis in myocardium to maintain systolic function during cardiac hypertrophy. Indeed, an angiogenesis inhibitor, TNP-470, not only suppressed the development of cardiac hypertrophy but also impaired cardiac function even at the adaptive phase. Conversely, promoting angiogenesis by introduction of VEGF and angiopoietin 1 to the TAC heart promoted cardiac hypertrophy with preserved systolic function even at the maladaptive phase. These results further indicate that angiogenesis is enough and necessary for the development of cardiac hypertrophy and maintenance of cardiac function[21].Consistent with these histological findings of vasculature in hypertrophied myocardium, expressions of VEGF and angiopoietin1 were increased in the adaptive phase and then decreased in the maladaptive phase.A key regulator of angiogenesis under the condition of hypoxia, hypoxia-inducible factor-1 (Hif-1), was markedly upregulated in the adaptive phase and was significantly decreased in the maladaptive phase[21].Hif-1 is stabilized under hypoxic condition and activates the transcription of various hypoxia-associated genes such as erythropoietin and VEGF genes[23, 24]. To evaluate specific roles of Hif-1 $\alpha$ in the heart, we analyzed inducible cardiomyocyte-specific deletion of Hif-1 $\alpha$ by using $\alpha \mathrm{MHC}$ promoter driven MerCreMer and tamoxifen. In the Hif- $1 \alpha$-deleted mice, cardiac hypertrophy and systolic function were significantly suppressed even in the adaptive phase, suggesting that Hif-1 is an important mediator for cardiac growth and maintenance 
of cardiac function.It has been reported that cardiomyocyte hypertrophy increases diffusion distance and reduces oxygen supply in the myocardium. Indeed, in hypertrophied TAC heart, hypoxia wasinduced and sustained until day 28[21]. This observation raises the next question why Hif-1 $\alpha$ was downregulated even under the hypoxic condition at 4 weeks after TAC.

\section{4. p53 inhibits Hif-1 in hypoxic myocardium}

A tumor suppressor, p53, is kept at very low level in the normal heart but is upregulated when cardiomyocytes are exposed to hypoxic stressesby pressure overload and coronary artery ligation as well as genotoxic stresseswith adriamycin treatment[21, 25, 26]. We have also found an increase in p53 expression in the murine heart of dilated cardiomyopathy (DCM) model, in which mutated cardiac $\alpha$-actin detected in human DCM patients is overexpressed specifically in the cardiac myocytes [27], suggesting that elevation of p53 expression not only reflects the stressed status of the heart, but also plays a key role in the common pathway toward HF.Hif-1 plays important roles in hypoxia-induced p53 accumulation and potentiates p53 regulating gene transcription via direct binding[28],and it has been also reported that severe and/or sustained hypoxia induces p53 expression that inhibits the function or promotes degradation of HIF-1 To elucidate the role of p53 in the cardiac hypertrophy, we imposed pressure overload on p53 knockout mice. Expressions of Hif-1 and VEGF were significantly higherin the heart of p53 knockout mice compared with wild-type mice at maladaptive phase.Consequently, 
capillary density was significantly increased and cardiac function was conserved in p53-deficient mice even at maladaptive phase. Next, we examined the effects of p53 activation by administrating quinacrine, a p53 activator, to mice with TAC. Quinacrine treatment upregulated p53, and decreased expression ofHif-1 and VEGF. Quinacrine treatment significantly decreased capillary density, and suppressed cardiac hypertrophy and cardiac functioneven in the adaptive phase. Together, these results indicate novel molecular mechanisms underlying transition of cardiac hypertrophy to HF;p53 inhibits angiogenesis by suppressing HIF-1, resulting in myocardial hypoxia and cardiac dysfunction (Figure 1).

\section{Angiogenesis as a potential therapeutic strategy for heart failure}

If the hypoxia is a cause of HF, induction of angiogenesis might be a novel strategy for HF. In our previous studies of angiogenic therapy for animal models and human patients with limb ischemia, implantation of peripheral blood mononuclear cells (PB-MNC) into skeletal muscle significantly improved limb ischemia by upregulation of various kinds of angiogenic growth factors from the regenerated muscle[29, 30].Most of the patients of limb ischemia have ischemia also in the heart and some of them showed cardiac dysfunction. Implantation of PB-MNC into skeletal muscle improved cardiac function as well as cardiac ischemia possibly by angiogenic growth factors which are secreted from the skeletal muscles[30]. These findings also support our concept that the development of HF is caused by myocardial ischemia (Figure 2). 
Several strategies to enhance myocardial angiogenesis have been investigated, including delivery of proteins or complementary DNAs of angiogenic growth factors such as VEGF-A [31-34], VEGF-B [35-37], fibroblast growth factor-2 (FGF-2) [33, 38, 39], FGF-5 [40, 41], stromal cell-derived factor-1 (SDF-1) [42, 43], hepatocyte growth factor (HGF) [44], and midkine [45]. Although long-term stimulation with VEGF-A promotes immature angiogenesis and increases vascular permeability [46], simultaneous administrationof VEGF-A and angiopoietin1 yields coordinated vascular growth and improves the perfusion and function of the diseased hearts [34, 47, 48]. Another potential therapeutic target is Hif-1[49]. Cobalt, which is known to stabilize Hif-1 $\alpha$, prevented decline in contractile function of perfused rat hearts under hypoxia-reoxygenation [50]. According to recent studies, cobalt-induced stabilization of Hif-1 $\alpha$ is dependent on copper [51, 52], and copper supplementation reversed cardiac contractility and prevented the development of HF in pressure overloaded mice at least in part via induction of myocardial angiogenesis[53].

\section{IGFBP-4is a novel cardiogenic factor by inhibiting Wnt/ $\beta$-catenin signaling}

Another therapeutic strategy for HF is cardiomyogenesis, and there are two methods to increase cardiomyocytes, 1) cell transplantation of culturedcardiomyocytes and 2) induction of differentiation of cardiac stem cells into cardiomyocytes or of proliferation of cardiac myocytes. Although there are lots of candidate cell types for cell transplantationsuch ashematopoietic stem cells, mesenchymal stem cells, side population 
cellsand resident stem cells[54], only embryonic stem (ES) cells or induced pluripotent stem (iPS) cells can efficiently differentiate into cardiomyocytes. There are still many issues even inES cells and iPS cells to be implanted into human hearts such as immaturity and differentiation efficiency[55],and thus it is important to improve the quality and efficiency of cardiomyocyte differentiation.

It has been thought that cardiomyocytes are terminally differentiated and withdrawn from the cell cycle after birth. Therefore, myocardial damage due to myocardial infarction causes permanent loss of functional cardiomyocytes and results in cardiac dysfunction.Although manygroups including us have identified cardiac stem or progenitor cellssuch as Sca-1 positive cells $[56,57]$, c-kit positive cells [58], side population cells [59-61] and islet-1 positive cells[62, 63],these intrinsic stem-like cells do not contribute to the cardiac regeneration with unknown reasons. Strong mediators to induce cardiomyogenesis might be useful for regeneration therapy.

To identify a factor inducing cardiomyogenesis, we screened the cardiomyogenic activity of the media conditioned by many cell types using P19CL6 cells, which can be differentiated into beating cardiomyocytes withdimethylsulphoxide[64].Within the cell types we tested, media conditioned by murine stromal cell line OP9 effectively differentiated P19CL6 cells into cardiomyocytes without dimethylsulphoxide, indicating that OP9 cells secreted some cardiomyogenic factors[65]. To further identify OP9-derived cardiomyogenic factors, complementary DNA clones isolated by a signal sequence trap method from an OP9 cDNA library were screened for their ability of cardiomyogenesis by transient transfection into P19CL6 cells [66], and one of the genes 
which we identified as a cardiomyogenic factor secreted from OP9 cells was insulin-like growth factor-binding protein-4 (IGFBP-4).IGFBP-4 itself also induced cardiomyocyte differentiation of P19CL6 cells and ES cells [65].IGFBPs directly bind to IGFs and modulate their action, however, cardiogenic activity of IGFBP-4 is independent of

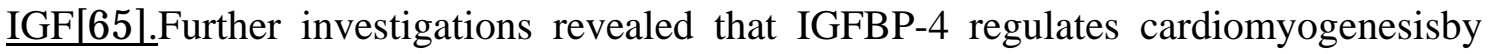
inhibiting canonical Wnt signaling pathway. IGFBP-4 physically interacted with cell surface receptors of Wnt/ $\beta$-catenin signaling, Frizzled and LRP5/6, and competitively inhibitedbinding of Wnt to the receptors [65]. In IGFBP-4 knockdown Xenopus, the embryonic heart was initially developed but subsequent growth and maturation were interfered, and the embryo resulted in severe heart defect[65], suggesting that IGFBP-4 plays important roles in cardiogenesis by preserving the proliferation and/or the survival of embryonic cardiomyocytes. In vivo, IGFBP-4 was expressed in the anterior liverwhich exists just next to the heartat late embryonic stage, and it has been reported that cardiac mesoderm secretes FGFs and induces liver development[67], suggesting that there are interactive paracrine signals coordinating the development of each organs between the heart and the liver primordia. In this way, IGFBP-4 is an inhibitory regulator of the canonical Wnt signaling which is required for embryonic cardiogenesis, and is a molecular linkage between IGF and Wnt signaling pathways(Figure 3). On the other hand, IGFBP-4 has been reported to have inhibitory effects on growth factor-induced angiogenesis in chick chorioallantoic membrane[68]. Therefore, further investigations are necessary to elucidate whether administration of IGFBP-4 is beneficial or not for the injured heart. 


\section{Conclusion}

In this review, we have summarized the "President's Distinguished Lecture Award” of XX World Congress of International Society for Heart Research 2010 in Kyoto, Japan. The recent advances of experimental techniques have revealed pathophysiology of various diseasesincluding HF, however, we have not identified the key molecules to be targeted by drugs in HF.Many molecular target-based drugs have been recently developed in particular for cancers based on their molecular and cellular mechanisms, and the prognosis of patients with some cancers has become much improved. Although cancers are verydifferent fromHF in many aspects, the elucidation of molecular mechanisms and

the development of molecular target-based drugs for HF based on its mechanisms might be very important. 


\section{Acknowledgements}

I. K. was supported by grants from the Ministry of Education, Culture, Sports, Science and Technology (MEXT); the Ministry of Health, Labor, and Welfare; and Japan Science and Technology Agency. T.O. was supported by grant from the Takeda Science Foundation. 


\section{References}

[1] Oka T, Xu J, Molkentin JD. Re-employment of developmental transcription factors in adult heart disease. Semin Cell Dev Biol. 2007;18:117-31.

[2] Anderson ME, Brown JH, Bers DM. CaMKII in myocardial hypertrophy and heart failure. J Mol Cell Cardiol.51:468-73.

[3] Dorn GW, 2nd. Mechanisms of non-apoptotic programmed cell death in diabetes and heart failure. Cell Cycle.9:3442-8.

[4] Berk BC, Fujiwara K, Lehoux S. ECM remodeling in hypertensive heart disease. J Clin Invest. 2007;117:568-75.

[5] Spinale FG. Myocardial matrix remodeling and the matrix metalloproteinases: influence on cardiac form and function. Physiol Rev. 2007;87:1285-342.

[6] Sanada S, Komuro I, Kitakaze M. Pathophysiology of myocardial reperfusion injury: preconditioning, postconditioning, and translational aspects of protective measures. Am J Physiol Heart Circ Physiol.301:H1723-41.

[7] Abel ED, Doenst T. Mitochondrial adaptations to physiological vs. pathological cardiac hypertrophy. Cardiovasc Res.90:234-42.

[8] Katz AM. Proliferative signaling and disease progression in heart failure. Circ J. 2002;66:225-31.

[9] Gordon JW, Shaw JA, Kirshenbaum LA. Multiple facets of NF-kappaB in the heart: to be or not to NF-kappaB. Circ Res.108:1122-32.

[10] Leask A. The role of endothelin-1 signaling in the fibrosis observed in systemic sclerosis. Pharmacol Res.

[11] Leask A. Targeting the TGFbeta, endothelin-1 and CCN2 axis to combat fibrosis in scleroderma. Cell Signal. 2008;20:1409-14.

[12] Chang CP, Bruneau BG. Epigenetics and cardiovascular development. Annu Rev Physiol.74:41-68.

[13] Yamazaki J, Igarashi M, Nakata M, Okamoto K, Hosoi H, Morishita T, et al. Estimating myocardial damage and the need for surgery in patients with valvular heart 
disease by Tl-201 SPECT. Clin Nucl Med. 1996;21:855-63.

[14] Hudlicka O, Brown M, Egginton S. Angiogenesis in skeletal and cardiac muscle. Physiol Rev. 1992;72:369-417.

[15] Shiojima I, Sato K, Izumiya Y, Schiekofer S, Ito M, Liao R, et al. Disruption of coordinated cardiac hypertrophy and angiogenesis contributes to the transition to heart failure. J Clin Invest. 2005;115:2108-18.

[16] Izumiya Y, Shiojima I, Sato K, Sawyer DB, Colucci WS, Walsh K. Vascular endothelial growth factor blockade promotes the transition from compensatory cardiac hypertrophy to failure in response to pressure overload. Hypertension. 2006;47:887-93.

[17] Heineke J, Auger-Messier M, Xu J, Oka T, Sargent MA, York A, et al. Cardiomyocyte GATA4 functions as a stress-responsive regulator of angiogenesis in the murine heart. J Clin Invest. 2007;117:3198-210.

[18] Molkentin JD. The zinc finger-containing transcription factors GATA-4, -5, and -6. Ubiquitously expressed regulators of tissue-specific gene expression. J Biol Chem. 2000;275:38949-52.

[19] Oka T, Maillet M, Watt AJ, Schwartz RJ, Aronow BJ, Duncan SA, et al. Cardiac-specific deletion of Gata4 reveals its requirement for hypertrophy, compensation, and myocyte viability. Circ Res. 2006;98:837-45.

[20] Walsh K, Shiojima I. Cardiac growth and angiogenesis coordinated by intertissue interactions. J Clin Invest. 2007;117:3176-9.

[21] Sano M, Minamino T, Toko H, Miyauchi H, Orimo M, Qin Y, et al. p53-induced inhibition of Hif-1 causes cardiac dysfunction during pressure overload. Nature. 2007;446:444-8.

[22] Aoyagi T, Fujii AM, Flanagan MF, Arnold LW, Brathwaite KW, Colan SD, et al. Transition from compensated hypertrophy to intrinsic myocardial dysfunction during development of left ventricular pressure-overload hypertrophy in conscious sheep. Systolic dysfunction precedes diastolic dysfunction. Circulation. 1993;88:2415-25.

[23] Wang GL, Semenza GL. General involvement of hypoxia-inducible factor 1 in transcriptional response to hypoxia. Proc Natl Acad Sci U S A. 1993;90:4304-8.

[24] Wang GL, Jiang BH, Rue EA, Semenza GL. Hypoxia-inducible factor 1 is a basic-helix-loop-helix-PAS heterodimer regulated by cellular $\mathrm{O} 2$ tension. Proc Natl Acad Sci U S A. 1995;92:5510-4.

[25] Yoshida M, Shiojima I, Ikeda H, Komuro I. Chronic doxorubicin cardiotoxicity is 
mediated by oxidative DNA damage-ATM-p53-apoptosis pathway and attenuated by pitavastatin through the inhibition of Rac1 activity. J Mol Cell Cardiol. 2009;47:698-705. [26] Naito AT, Okada S, Minamino T, Iwanaga K, Liu ML, Sumida T, et al. Promotion of CHIP-mediated p53 degradation protects the heart from ischemic injury. Circ Res. 2010;106:1692-702.

[27] Toko H, Takahashi H, Kayama Y, Oka T, Minamino T, Okada S, et al. $\mathrm{Ca} 2+/$ calmodulin-dependent kinase IIdelta causes heart failure by accumulation of p53 in dilated cardiomyopathy. Circulation. 2010;122:891-9.

[28] An WG, Kanekal M, Simon MC, Maltepe E, Blagosklonny MV, Neckers LM. Stabilization of wild-type p53 by hypoxia-inducible factor 1alpha. Nature. 1998;392:405-8.

[29] Tateno K, Minamino T, Toko H, Akazawa H, Shimizu N, Takeda S, et al. Critical roles of muscle-secreted angiogenic factors in therapeutic neovascularization. Circ Res. 2006;98:1194-202.

[30] Moriya J, Minamino T, Tateno K, Shimizu N, Kuwabara Y, Sato Y, et al. Long-term outcome of therapeutic neovascularization using peripheral blood mononuclear cells for limb ischemia. Circulation Cardiovascular interventions. 2009;2:245-54.

[31] Pearlman JD, Hibberd MG, Chuang ML, Harada K, Lopez JJ, Gladstone SR, et al. Magnetic resonance mapping demonstrates benefits of VEGF-induced myocardial angiogenesis. Nat Med. 1995;1:1085-9.

[32] Losordo DW, Vale PR, Symes JF, Dunnington CH, Esakof DD, Maysky M, et al. Gene therapy for myocardial angiogenesis: initial clinical results with direct myocardial injection of phVEGF165 as sole therapy for myocardial ischemia. Circulation. 1998;98:2800-4.

[33] Hughes GC, Biswas SS, Yin B, Coleman RE, DeGrado TR, Landolfo CK, et al. Therapeutic angiogenesis in chronically ischemic porcine myocardium: comparative effects of bFGF and VEGF. Ann Thorac Surg. 2004;77:812-8.

[34] Zhou L, Ma W, Yang Z, Zhang F, Lu L, Ding Z, et al. VEGF165 and angiopoietin-1 decreased myocardium infarct size through phosphatidylinositol-3 kinase and Bcl-2 pathways. Gene Ther. 2005;12:196-202.

[35] Pepe M, Mamdani M, Zentilin L, Csiszar A, Qanud K, Zacchigna S, et al. Intramyocardial VEGF-B167 gene delivery delays the progression towards congestive failure in dogs with pacing-induced dilated cardiomyopathy. Circulation research. 
2010;106:1893-903.

[36] Serpi R, Tolonen AM, Huusko J, Rysa J, Tenhunen O, Yla-Herttuala S, et al. Vascular endothelial growth factor-B gene transfer prevents angiotensin II-induced diastolic dysfunction via proliferation and capillary dilatation in rats. Cardiovasc Res. 2011;89:204-13.

[37] Huusko J, Lottonen L, Merentie M, Gurzeler E, Anisimov A, Miyanohara A, et al. AAV9-mediated VEGF-B gene transfer improves systolic function in progressive left ventricular hypertrophy. Mol Ther. 2012;20:2212-21.

[38] Battler A, Scheinowitz M, Bor A, Hasdai D, Vered Z, Di Segni E, et al. Intracoronary injection of basic fibroblast growth factor enhances angiogenesis in infarcted swine myocardium. J Am Coll Cardiol. 1993;22:2001-6.

[39] Laham RJ, Chronos NA, Pike M, Leimbach ME, Udelson JE, Pearlman JD, et al. Intracoronary basic fibroblast growth factor (FGF-2) in patients with severe ischemic heart disease: results of a phase I open-label dose escalation study. J Am Coll Cardiol. 2000;36:2132-9.

[40] Giordano FJ, Ping P, McKirnan MD, Nozaki S, DeMaria AN, Dillmann WH, et al. Intracoronary gene transfer of fibroblast growth factor-5 increases blood flow and contractile function in an ischemic region of the heart. Nat Med. 1996;2:534-9.

[41] Suzuki G, Lee TC, Fallavollita JA, Canty JM, Jr. Adenoviral gene transfer of FGF-5 to hibernating myocardium improves function and stimulates myocytes to hypertrophy and reenter the cell cycle. Circulation research. 2005;96:767-75.

[42] Sundararaman S, Miller TJ, Pastore JM, Kiedrowski M, Aras R, Penn MS. Plasmid-based transient human stromal cell-derived factor-1 gene transfer improves cardiac function in chronic heart failure. Gene Ther. 2011;18:867-73.

[43] Kanki S, Segers VF, Wu W, Kakkar R, Gannon J, Sys SU, et al. Stromal cell-derived factor-1 retention and cardioprotection for ischemic myocardium. Circ Heart Fail. 2011;4:509-18.

[44] Siltanen A, Kitabayashi K, Lakkisto P, Makela J, Patila T, Ono M, et al. hHGF overexpression in myoblast sheets enhances their angiogenic potential in rat chronic heart failure. PLoS One. 2011;6:e19161.

[45] Sumida A, Horiba M, Ishiguro H, Takenaka H, Ueda N, Ooboshi H, et al. Midkine gene transfer after myocardial infarction in rats prevents remodelling and ameliorates cardiac dysfunction. Cardiovasc Res. 2010;86:113-21. 
[46] Weis SM, Cheresh DA. Pathophysiological consequences of VEGF-induced vascular permeability. Nature. 2005;437:497-504.

[47] Su H, Takagawa J, Huang Y, Arakawa-Hoyt J, Pons J, Grossman W, et al. Additive effect of AAV-mediated angiopoietin-1 and VEGF expression on the therapy of infarcted heart. Int J Cardiol. 2009;133:191-7.

[48] Tao Z, Chen B, Tan X, Zhao Y, Wang L, Zhu T, et al. Coexpression of VEGF and angiopoietin-1 promotes angiogenesis and cardiomyocyte proliferation reduces apoptosis in porcine myocardial infarction (MI) heart. Proc Natl Acad Sci U S A. 2011;108:2064-9. [49] Semenza GL. Hypoxia-inducible factors in physiology and medicine. Cell. 2012;148:399-408.

[50] Endoh H, Kaneko T, Nakamura H, Doi K, Takahashi E. Improved cardiac contractile functions in hypoxia-reoxygenation in rats treated with low concentration $\mathrm{Co}(2+)$. Am $\mathrm{J}$ Physiol Heart Circ Physiol. 2000;279:H2713-9.

[51] Feng W, Ye F, Xue W, Zhou Z, Kang YJ. Copper regulation of hypoxia-inducible factor-1 activity. Mol Pharmacol. 2009;75:174-82.

[52] Qiu L, Ding X, Zhang Z, Kang YJ. Copper is required for cobalt-induced transcriptional activity of hypoxia-inducible factor-1. J Pharmacol Exp Ther. 2012;342:561-7.

[53] Jiang Y, Reynolds C, Xiao C, Feng W, Zhou Z, Rodriguez W, et al. Dietary copper supplementation reverses hypertrophic cardiomyopathy induced by chronic pressure overload in mice. J Exp Med. 2007;204:657-66.

[54] Dimmeler S, Zeiher AM, Schneider MD. Unchain my heart: the scientific foundations of cardiac repair. J Clin Invest. 2005;115:572-83.

[55] Laflamme MA, Murry CE. Regenerating the heart. Nat Biotechnol. 2005;23:845-56. [56] Oh H, Bradfute SB, Gallardo TD, Nakamura T, Gaussin V, Mishina Y, et al. Cardiac progenitor cells from adult myocardium: homing, differentiation, and fusion after infarction. Proc Natl Acad Sci U S A. 2003;100:12313-8.

[57] Matsuura K, Nagai T, Nishigaki N, Oyama T, Nishi J, Wada H, et al. Adult cardiac Sca-1-positive cells differentiate into beating cardiomyocytes. J Biol Chem. 2004;279:11384-91.

[58] Beltrami AP, Barlucchi L, Torella D, Baker M, Limana F, Chimenti S, et al. Adult cardiac stem cells are multipotent and support myocardial regeneration. Cell. 2003;114:763-76. 
[59] Goodell MA, Brose K, Paradis G, Conner AS, Mulligan RC. Isolation and functional properties of murine hematopoietic stem cells that are replicating in vivo. J Exp Med. 1996;183:1797-806.

[60] Tomita Y, Matsumura K, Wakamatsu Y, Matsuzaki Y, Shibuya I, Kawaguchi H, et al. Cardiac neural crest cells contribute to the dormant multipotent stem cell in the mammalian heart. J Cell Biol. 2005;170:1135-46.

[61] Oyama T, Nagai T, Wada H, Naito AT, Matsuura K, Iwanaga K, et al. Cardiac side population cells have a potential to migrate and differentiate into cardiomyocytes in vitro and in vivo. J Cell Biol. 2007;176:329-41.

[62] Cai CL, Liang X, Shi Y, Chu PH, Pfaff SL, Chen J, et al. Isl1 identifies a cardiac progenitor population that proliferates prior to differentiation and contributes a majority of cells to the heart. Dev Cell. 2003;5:877-89.

[63] Laugwitz KL, Moretti A, Lam J, Gruber P, Chen Y, Woodard S, et al. Postnatal isl1+ cardioblasts enter fully differentiated cardiomyocyte lineages. Nature. 2005;433:647-53. [64] Monzen K, Shiojima I, Hiroi Y, Kudoh S, Oka T, Takimoto E, et al. Bone morphogenetic proteins induce cardiomyocyte differentiation through the mitogen-activated protein kinase kinase kinase TAK1 and cardiac transcription factors Csx/Nkx-2.5 and GATA-4. Mol Cell Biol. 1999;19:7096-105.

[65] Zhu W, Shiojima I, Ito Y, Li Z, Ikeda H, Yoshida M, et al. IGFBP-4 is an inhibitor of canonical Wnt signalling required for cardiogenesis. Nature. 2008;454:345-9.

[66] Ueno H, Sakita-Ishikawa M, Morikawa Y, Nakano T, Kitamura T, Saito M. A stromal cell-derived membrane protein that supports hematopoietic stem cells. Nat Immunol. 2003;4:457-63.

[67] Jung J, Zheng M, Goldfarb M, Zaret KS. Initiation of mammalian liver development from endoderm by fibroblast growth factors. Science. 1999;284:1998-2003.

[68] Contois LW, Nugent DP, Caron JM, Cretu A, Tweedie E, Akalu A, et al. Insulin-like growth factor binding protein-4 differentially inhibits growth factor-induced angiogenesis. J Biol Chem. 2012;287:1779-89. 


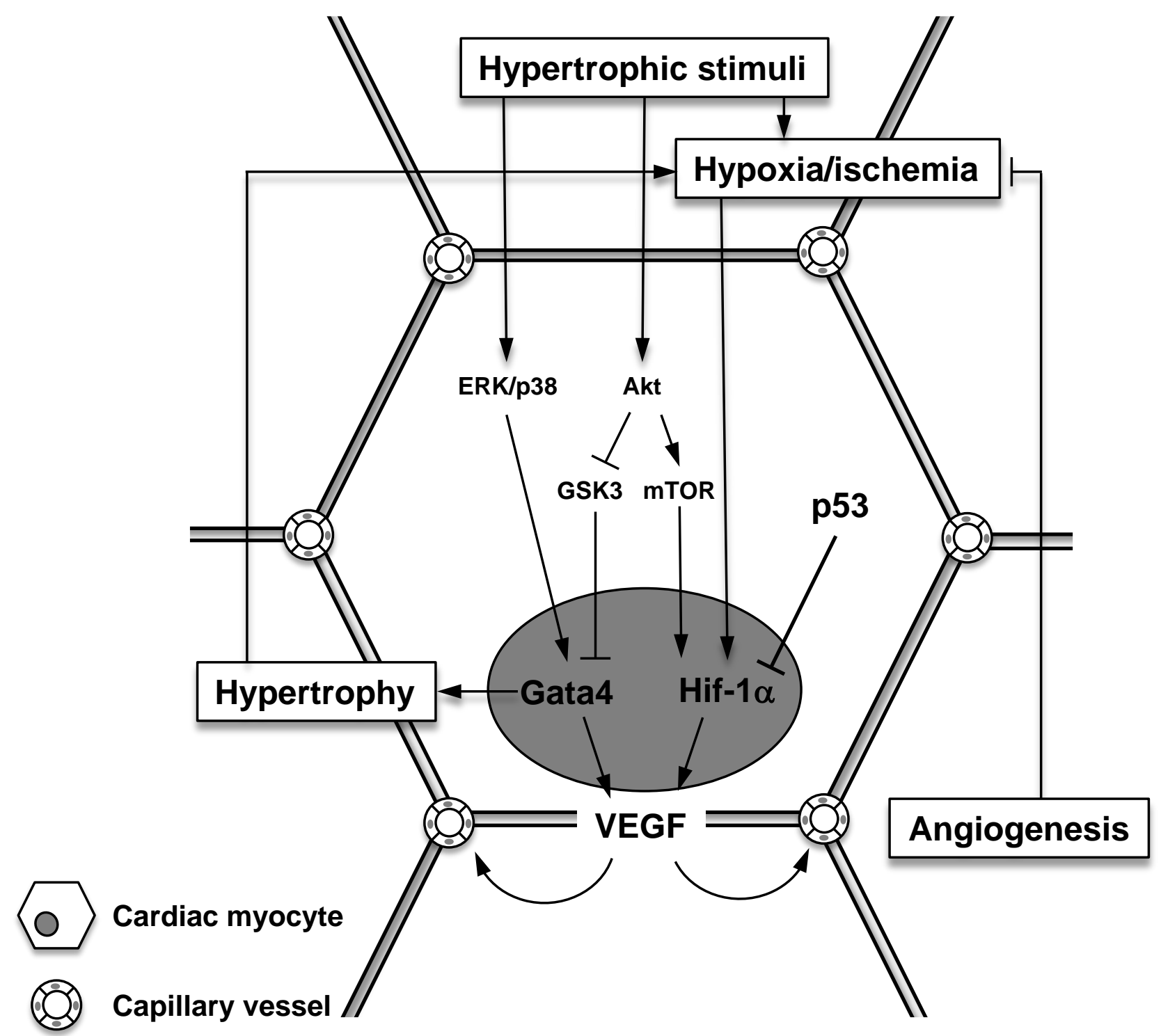

Figure 1. Molecular mechanism of cardiac hypertrophy and angiogenesis. 


\section{Muscle ischemic lesion}

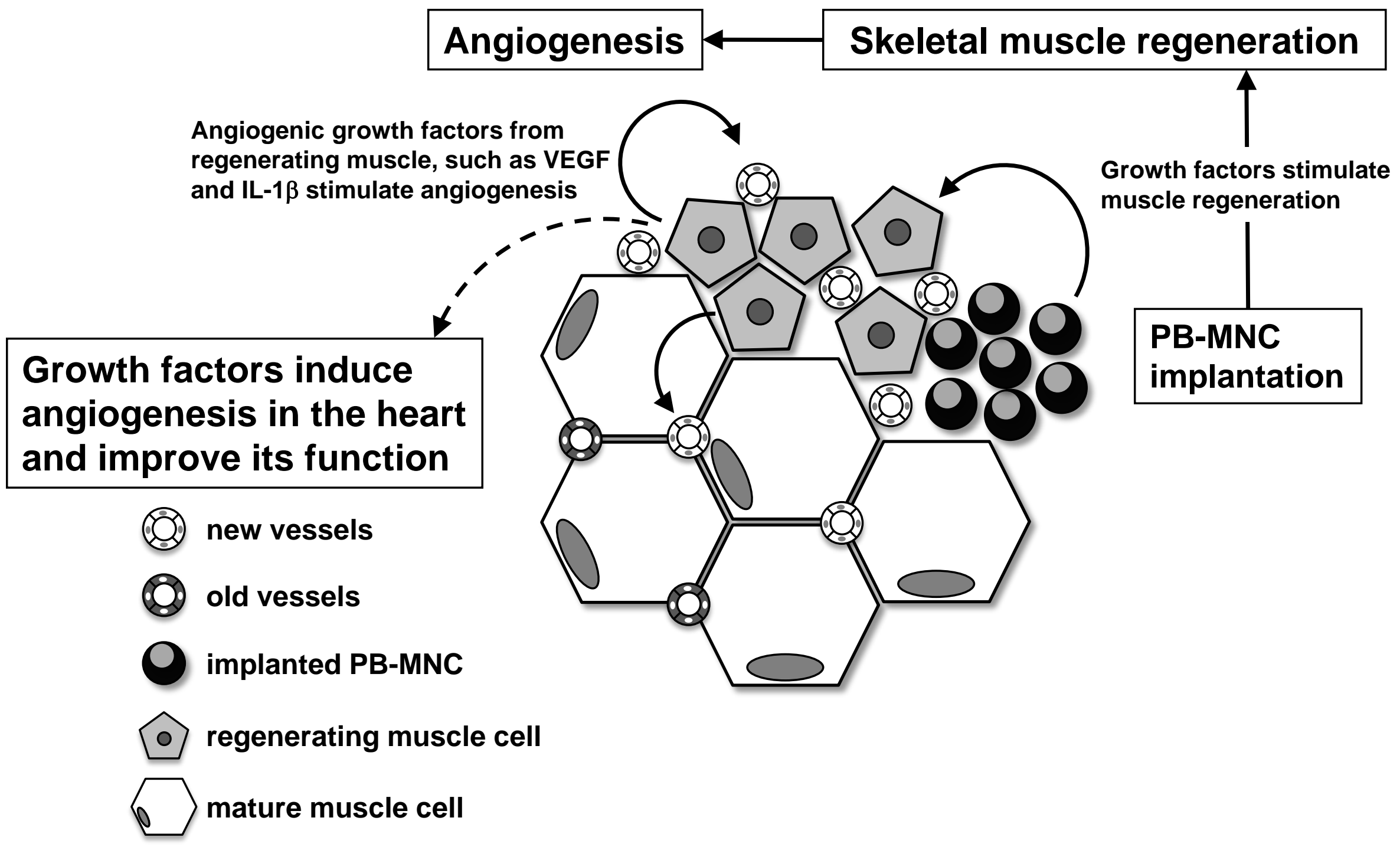

Figure 2. Molecular mechanisms of angiogenesis induced by PB-MNC. 


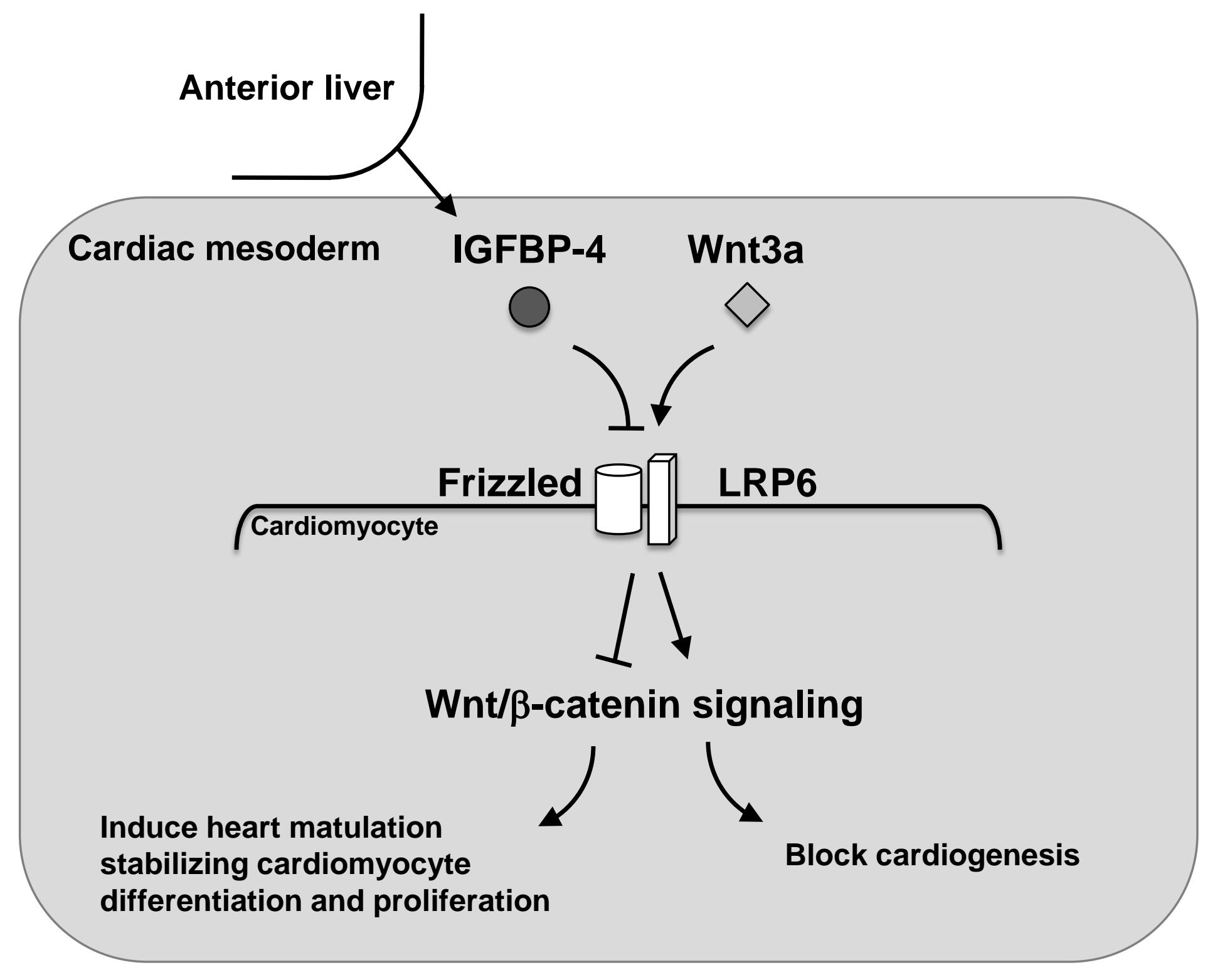

Figure 3. IGFBP-4 induces cardiogenesis by inhibiting Wnt/ $\beta$-catenin signaling. 